\title{
Intergenerational Dependence in Education and Income
}

\author{
Paul A. Johnson \\ Department of Economics \\ Vassar College \\ Poughkeepsie, NY 12604-0030
}

April 27, 1998

Some of the work for this paper was done while I was at the University of Oregon. I thank Cathleen Leué and the staff of the Data Services Laboratory at the University of Oregon for their assistance in obtaining the data. This work has benefited from comments by Steven Durlauf, George Evans, Larry Singell, John Smith, Joe Stone, and Jim Ziliak All errors are mine. 
This paper takes up Goldberger's [1989] suggestion to investigate the links across generations using nonmonetary measures of status. I find that the links in educational attainment are somewhat stronger than, and statistically significant from, those in income even if the income data are adjusted for measurement errors as suggested by Solon [1992] and Zimmerman [1992]. This result accords well with the theoretical work of Galor and Zeira [1993] and others which emphases the role of market imperfections in human capital accumulation persistence.

JEL Classifications: D31, J24, O15. 


\section{Introduction}

Noting the disagreement between anecdotal and formal attempts to measure the intergenerational persistence in economic status, Solon [1992] and Zimmerman [1992], show that using annual income to measure economic status underestimates this persistence due to measurement errors. Correcting for these errors by using averages of annual income over several years to measure status, they find intergenerational correlations implying much less mobility in the income distribution than previous studies. In this paper I use educational attainment to measure the intergenerational persistence in economic status as attainment may be better correlated with lifetime earnings than income in any one year or the average over several adjacent years and this will further reduce the effects of measurement errors.

Educational attainment may also be better correlated with economic status measured in terms of welfare or real income as it more accurately reflects an individual's lifetime economic opportunities. The variations in incomes across individuals will misstate the variation in opportunities as the former is influenced by both the labor supply decision and choices between monetary and nonmonetary rewards from employment. For example, Bowles [1972] shows that, if high status individuals value nonmonetary rewards relative to monetary rewards more highly than low status individuals, the differences in incomes will understate the differences in opportunities. Goldberger [1989] warns against considering only monetary measures of status as the links across generations could be stronger for other measures.

\section{Data and Analysis}

The data are a sample of 295 father-son pairs drawn from the 1988 respondents file of the PSID. For a pair to be included in the sample the son had to have been aged between 5 and 15 years in 1968, and been the head of a household in 1987. The age restriction reduces the possibility that those sons who finish college and those who do not finish high school are under represented in the sample. Due to the use of average income to measure lifetime income, a father-son pair is included only if the son "split off" from the original family 
between 1970 and 1984 inclusive. Only pairs with either a white or black father are included as the PSID includes relatively few parents of other races. Some of the pairs satisfying the above criterion have sons who are brothers and so have the same father. In such cases, a pair selected randomly from those with the same father is included in the sample and the remainder discarded as inclusion of brothers in the sample would result in data that violates the assumption of independent observations required for consistentcy of the estimators used here. As the probability of inclusion in the PSID sample is not the same for each observation, all of the calculations in this paper have been appropriately weighted using weights based on those provided in the PSID. ${ }^{1}$

The PSID gives data on the educational attainment of both fathers and sons in the form of categories such as "12 grades and no further training". In order to ensure adequate numbers of transitions from each category some of these have been combined here to leave four categories for the analysis here. They are: "0 to 11 grades" (Category 1); "Completed high school but had no further education or training" (Category 2); "High school and other education or training but no college degree" (Category 3); and, "Bachelor's, professional, or advanced degree" (Category 4).

To analyze the persistence in the distribution of educational attainment across generations I use the data on father's and son's attainment to estimate markov transition matrices. $^{2}$ The idea is that persistence can be represented by the extent to which the probability distribution of a son's attainment depends on the attainment of his father. The

\footnotetext{
${ }^{1}$ The primary reason for the need to weight the calculations is the design of the PSID to include substantially more low-income families than would a random sample of the US population. See Hill [1992] for a discussion of this issue. The weight used is proportional to the inverse of the estimated probability of the child's inclusion in the sample. That is, the "1988 Individual Weight", as suggested by Hill [1992], modified to reflect the procedure used to eliminate siblings from the data. This modification involves multiplying the weight provided in the PSID by the number of sons with the same father. As only one of any such sons is included in the analysis and the included son is selected randomly from those with the same father, this adjustment to the weight reflects the consequent change in that individual's selection probability.

${ }^{2}$ An early application of markov chains to mobility issues can be found in Prais [1955]. For criticism of the markovian approach to social mobility see McFarland [1970] and Shorrocks [1976]. Zimmerman [1992] estimates intergenerational transition matrices for states defined by the quartiles of the distributions of wages, earnings, and the Duncan index of socioeconomic status, and finds evidence of status immobility.
} 
process of intergenerational transmission of educational attainment may not necessarily follow a stationary, first-order markov process. The stationarity assumption, in particular, is questionable. Nevertheless, the markovian framework is a useful one for summarizing the data provided the statistics presented are interpreted as describing the outcomes of the forces governing the intergenerational evolution of attainment during the 1960s, 70s, and 80s.

Table 1 presents the estimated transition matrix and the implied equilibrium distribution. The probability of transition from category $k$ to category $j$ is estimated by the quasi-maximum likelihood estimator $p_{k j}=w_{k j} / \sum_{j=1}^{4} w_{k j}$ where $w_{k j}$ is the sum of the weights of those father-son pairs who transition from category $k$ to category $j$ for $j, k=1, \ldots, 4$. The transition matrices estimated here satisfy the conditions under which the equilibrium distribution exists given in Feller [1970]. The equilibrium probability of being in category $k$ is $e_{k}$ for $k=1, \ldots, 4$, found as the solutions to $e_{k}=\sum_{j=1}^{4} e_{j} p_{j k}$ for $k=1, \ldots, 3$, and $\sum_{k=1}^{4} e_{k}=1$

Table 2 shows the estimated transition matrix and equilibrium distribution for the income data. This data is adjusted for measurement errors, cohort effects, the different positions of the fathers and sons in the life cycle, and racial differences in the age-earnings profile. $^{3}$ The transition matrix for the income distribution is estimated for states defined by

\footnotetext{
${ }^{3}$ Let $y_{i}^{f}$ be the income of father $i$ measured as average total family income from 1967 to 1969 in 1969 dollars and $y_{i}^{s}$ be that of son $i$ measured as average total family income from 1985 to 1987 in 1987 dollars. Averaging is one of the solutions to the measurement error problem suggested by Solon [1992] and Zimmerman [1992]. Strictly speaking, one need only average the father's income to reduce the problem in the regression context. Both father's and son's incomes are averaged here because this data is used later to estimate transition matrices. The model $\log y_{i}^{h}=\lambda_{0}^{h}+\lambda_{1}^{h} \bar{A}_{i}^{h}+\lambda_{2}^{h} \bar{S}_{i}^{h}+\lambda_{3}^{h} D_{i}^{\text {black }}+\lambda_{4}^{h} D_{i}^{\text {black }} \bar{A}_{i}^{h}+\lambda_{5}^{h} D_{i}^{\text {black }} \bar{S}_{i}^{h}+\epsilon_{i}^{h}$ for $h=s, f$ is fit to the data to adjust for cohort effects, the different positions of the fathers and sons in the life cycle, and racial differences in the age-earnings profile. Here, $\bar{A}_{i}^{h}$ is the average age of the individual, $\bar{S}_{i}^{h}$ is the average of the square of their age, with the averages taken over the same years as the income averages, and $D_{i}^{\text {black }}=1$ if the father in pair $i$ is black. The residuals, $\widehat{\epsilon}_{i}^{s}$ and $\widehat{\epsilon}_{i}^{f}$, are used as measures of the son's and father's income respectively. Fitting the model $\widehat{\epsilon}_{i}^{s}=\rho \widehat{\epsilon}_{i}^{f}+u_{i}$ yields $\widehat{\rho}=.48$ with an estimated standard error of 0.045 and $\widehat{\sigma}_{u}^{2}=.28$. This estimate of the elasticity of a son's economic status with respect to that of his father is close to those found by Solon [1992], Zimmerman [1992], and Cooper, Durlauf and Johnson [1993], suggesting that the markov transition matrix estimated from the $\widehat{\epsilon}_{i}^{j}$ s provides a measure of the persistence in economic status representative of those found in recent previous studies.
} 
imposing on income the same marginal distributions for the fathers and sons as for educational attainment. This means that, for example, as $41 \%$ of the fathers fall in category 1 for educational attainment, the lowest state in the income distribution for the fathers is defined as that containing the lowest $41 \%$ of the income measures.

A test of the hypothesis that matrix describing the transitions in educational attainment is the same as that describing transitions within the income distribution yields a $\chi^{2}$ test statistic of 37.6 with 12 degrees of freedom implying rejection at the $5 \%$ level. ${ }^{4}$ This rejection means that any differences in the measured mobility within the two distributions can be taken to be statistically significant.

Table 3 presents measures of mobility and immobility for the father-son pairs. Three measures are given:

(i) Batholemew's [1973] $D=\sum_{k=1}^{4} e_{k} \sum_{j=1}^{4} p_{k j}|k-j|$ which measures the mean number of category boundaries crossed during a transition; ${ }^{5}$

(ii) the "fraction of movers" $=1-\sum_{j=1}^{4} e_{j} p_{j j}$ which measures the fraction of the population moving to a different state during a transition; ${ }^{6}$ and,

(ii) the expected number of generations before leaving each category. ${ }^{7}$

\footnotetext{
${ }^{4}$ The test statistic is calculated as $\sum_{k=1}^{m} \sum_{j=1}^{m} n_{k}^{s} \frac{\left(p_{k j}^{e}-p_{k j}^{i}\right)^{2}}{p_{k j}}$ where $p_{k j}^{e}$ is the transition probability estimated from the education data, $p_{k j}^{i}$ is that estimated from the income data, and $n_{k}^{e}$ is the number of observations in category $k$ in the education data. As the weights have been scaled to sum to the number of observations in the sample, $n_{k}^{e}$ is the sum of the appropriate weights. Under the null hypothesis that $p_{k j}^{e}=p_{k j}^{i}$ for all $k$ and $j$, the statistic is asymptotically distributed as a $\chi^{2}$ random variable with $m(m-1)$ degrees of freedom [Anderson and Goodman, 1957]. Note that the application of this test here is only an approximation as it violates the assumption that the hypothesized transition matrix is a matrix of constants.

${ }^{5}$ Atkinson, Bourguignon, and Morrisson [1992] discuss some of the attributes of $D$. The main weakness in the current application is that the index treats all category boundaries as equal but a crossing from category 3 to category 4 is, for example, arguably different from a crossing from category 2 to category 3.

${ }^{6}$ The fraction of movers, normalized by $\frac{m-1}{m}$, satisfies the properties suggested in Shorrocks' [1978] axiomatic approach to mobility measures for the class of matrices having quasi-maximal diagonals. Restriction to this class is sufficient to ensure consistency of the properties and appears not to exclude any estimates found in the mobility literature.

${ }^{7}$ As Prais [1955] observes, the distribution of the number transitions, $t$, until departure from category $j$ given beginning in category $j$ is geometric. That is, $f_{j}(t)=\left(1-p_{j j}\right) p_{j j}^{t-1}$ so the expected number of transitions until
} 
In the first two cases, higher numbers imply more mobility while in the third, higher numbers imply less mobility.

By all of the measures the Table, the mobility in the income distribution exceeds that in the distribution of attainment. For example, the mean duration of a stay in any category is 1.57 generations for income and 1.71 generations for education. This suggests that, to the extent that attainment is preferable to income as a measure of economic status, the mobility in the income distribution overstates that in the distribution of status. This claim is reinforced by the fact that no attempt has been made to adjust the measures of educational attainment for cohort effects. To the extent that the average education of individuals has tended to rise over time, the average son ought to be better educated than his father so the analysis here will overstate the mobility in attainment.

\section{Conclusion}

This paper takes up Goldberger's [1989] suggestion to investigate the links across generations using nonmonetary measures of status. I find that the links in educational attainment are somewhat stronger than, and statistically significant from, those in income even if the income data are adjusted for measurement errors as suggested by Solon [1992] and Zimmerman [1992]. This result accords well with the theoretical work of Galor and Zeira [1993] and others which emphases the role of market imperfections in human capital accumulation persistence

leaving is $E_{j}=\frac{1}{1-p_{j j}}$. The expected number of transitions until leaving any category, $E$, is the average of the $E_{j}$ over the equilibrium distribution, $E=\sum_{j=1}^{m} e_{j} E_{j}$. 


\section{References}

Anderson, T.W., and L.A. Goodman, [1957], "Statistical Inference about Markov Chains," Annals of Mathematical Statistics, 28:89-110.

Atkinson, A. B., F. Bourguignon, and C. Morrisson, [1992], Empirical Studies of Earnings Mobility, Harwood Academic Publishers, Chur.

Bartholomew, D.J., [1973], Stochastic Models for Social Processes, John Wiley and Sons, London.

Bowles, Samuel, [1972], "Schooling and Inequality from Generation to Generation," Journal of Political Economy, 80:S219-51.

Cooper, Suzanne J., Steven N. Durlauf, and Paul A. Johnson, [1993], "On the Evolution of Economic Status Across Generations," Proceedings of the Business and Economic Statistics Section, American Statistical Association, 50-8.

Feller, William, [1970], An Intoduction to Probability Theory and Its Applications, Volume 1, 3rd Edition, John Wiley \& Sons, New York.

Galor, Oded and Joseph Zeira, [1993], "Income Distribution and Macroeconomics", Review of Economic Studies, 60:35-52.

Goldberger, Arthur S., [1989], "Economic and Mechanical Models of Intergenerational Transmission," American Economic Review, 79:504-13.

Hill, Martha S., [1992], The Panel Study of Income Dynamics: A User's Guide, SAGE Publications, Newbury Park.

McCall, John J., [1971]. “A Markovian Model of Income Dynamics," Journal of the American Statistical Association, 66:439-47.

McFarland, David D., [1970], "Intragenerational Social Mobility as a Markov Process: including a Time-Stationary Markovian Model that Explains Observed Declines in Mobility Rates Over Time," American Sociological Review, 35:463-76.

Prais, S. J., [1955], “Measuring Social Mobility,” Journal of the Royal Statistical Society, A118:56-66.

Shorrocks, A. F., [1976] “Income Mobility and the Markov Assumption,” Economic Journal, 86:566-78.

Shorrocks, A. F., [1978], “The Measurement of Mobility,” Econometrica, 46:1013-24.

Solon, Gary, [1992], "Intergenerational Income Mobility in the United States," American Economic Review, $82: 393-408$.

Spilerman, Seymor, [1972], "The Analysis of Mobility Processes by the Introduction of Independent Variables into a Markov Chain," American Sociological Review, 37:277-94.

Zimmerman, David J., [1992], "Regression Toward Mediocrity in Economic Status," American Economic Review, 82:409-29. 
Table 1: Transition Matrix for Education Levels

\begin{tabular}{|c|c|c|c|c|}
\cline { 2 - 5 } \multicolumn{1}{c|}{} & \multicolumn{4}{c|}{ Son's Education Category } \\
\hline $\begin{array}{c}\text { Father's } \\
\text { Education } \\
\text { Category }\end{array}$ & 1 & 2 & 3 & 4 \\
\hline 1 & .303 & .281 & .327 & .089 \\
\hline 2 & .229 & .339 & .319 & .113 \\
\hline 3 & .129 & .236 & .492 & .143 \\
\hline 4 & .000 & .116 & .505 & .379 \\
\hline $\begin{array}{c}\text { Ergodic } \\
\text { Distribution }\end{array}$ & .160 & .249 & .425 & .166 \\
\hline
\end{tabular}

Table 2: Transition Matrix for Income Levels

\begin{tabular}{|c|c|c|c|c|}
\hline & \multicolumn{4}{|c|}{ Son's Income Category } \\
\hline $\begin{array}{l}\text { Father's } \\
\text { Income } \\
\text { Category }\end{array}$ & 1 & 2 & 3 & 4 \\
\hline 1 & .282 & .326 & .292 & .099 \\
\hline 2 & .275 & .111 & .484 & .130 \\
\hline 3 & .087 & .273 & .476 & .163 \\
\hline 4 & .057 & .189 & .441 & .312 \\
\hline $\begin{array}{c}\text { Ergodic } \\
\text { Distribution }\end{array}$ & .156 & .230 & .443 & .171 \\
\hline
\end{tabular}


Table 3: Measures of Mobility and Immobility for Father-Son Pairs

\begin{tabular}{|c|c|c|c|c|c|c|c|}
\cline { 3 - 7 } \multicolumn{2}{c}{} & \multicolumn{5}{c|}{} & \multicolumn{5}{c|}{ Expected Generations Before Leaving Category } \\
\cline { 2 - 8 } \multicolumn{1}{c|}{} & $D$ & $\begin{array}{c}\text { Fraction } \\
\text { of Movers }\end{array}$ & 1 & 2 & 3 & 4 & Any \\
\hline Income & .86 & .67 & 1.39 & 1.13 & 1.91 & 1.46 & 1.57 \\
\hline Education & .78 & .60 & 1.44 & 1.51 & 1.97 & 1.61 & 1.71 \\
\hline
\end{tabular}

This table shows the measures of mobility and immobility for the transitions in the distributions of income and education for the subsample of 295 father-son pairs. The measures are described in the text. 